\title{
Maximising student learning through minimising information search time; the role of satisficing and skimming
}

\section{Dr Susan C Wilkinson}

University of Wales Institute Cardiff, UK

\begin{abstract}
With the increase in the use of the internet for educational purposes, the problem is no longer how to find and access information on-line, but how to select the most appropriate sources of information. What strategies do students adopt in order to allocate time adaptively to the information they need to learn? How and when do they make decision judgements, and how can this enable educators to facilitate student learning? If we understand how students search and retrieve information from texts, then we can design our texts to facilitate this process and ultimately enhance learning through minimising the time it takes for students to search for information within a text, and maximise the time they have for learning that information. This paper will present a new and innovative model of adaptive allocation of time across on-line texts, based on the principles of satisficing and skimming. It will discuss how knowledge about students' information search and retrieval processes can aid educational text designers in designing texts that will enhance student learning.
\end{abstract}

Keywords: information foraging; student learning; satisficing; skimming.

\section{Introduction}

The world consists of information societies, that is, societies where modern day living centres around the creation, processing, communication, use, and evaluation of information (Rice et al, 2001). Information seeking behaviour is a topic which is much debated and researched (e.g. Pirolli and Card, 1999; Sandstrom, 1994; O'Connor, 1993) and efforts indicate a shift in emphasis onto the user in order to inform the design of information systems and on-line learning environments. 
This paper aims to address a widespread problem concerning the increase in the use of the internet for educational purposes and how students are able to allocate their time and select the most appropriate sources of information. Students are often under a great deal of time pressure when searching for information on-line, and are therefore under pressure to find adaptive strategies to ensure they allocate their time effectively. Indeed, it has been a social aim for some time to improve people's ability to access and make sense of available information and this aim has also been implicated in efforts to improve modern day productivity (see Pirolli and Card, 1999).

The issue of time allocation to information sources has been argued by Pirolli and Card (1999) to be analogous to the problem of how animals forage for food. Other research has shown that time allocation across tasks varies with factors such as difficulty and time (Son and Metcalfe, 2000; Thiede and Dunlosky, 1999). This paper discusses a model of time allocation that is based on the way in which students search for information amongst sources that are all potentially relevant (e.g. similar to the results one may encounter when using an internet search engine). When students are experiencing information overload, what strategies do they use to adaptively allocate their time?

Once the model has been explained, the paper will continue to explore how an understanding of the way in which students search and retrieve information from on-line texts can influence text design in a way that will facilitate student learning by minimising information search time.

\section{Information foraging theory}

Miller (1983) described humans as 'informavores', based on the observation that we actively seek, compile, digest, and share information to a spectacular degree. As humans surrounded with information richness, we are constantly forced to choose between multiple information sources according to our goals and aims. To deal with this overload, we have developed sophisticated strategies that enable us to gather information, interpret this information, and use it to make decisions or solve problems (Dennett, 1991). Pirolli and Card (1999) view these information seeking strategies from an evolutionary ecological perspective. Their theory of information foraging is based on the fact that, 'when feasible, natural information systems evolve toward stable states that maximize gains of valuable 
information per unit cost' (Pirolli and Card, 1999: 642), people will adapt (e.g. their strategies) in order to maximise the gain they are able to achieve from a certain resource.

In the real world, where maximising is not practical due to time and resource constraints, rational choice may lead people to satisfice (i.e. stop searching after meeting some minimal requirement or when they have found something which is 'good enough') when making decisions rather than continuing to search for the optimal result. Simon (1976) points out that although people are adaptive in learning and choice situations, this adaptiveness still fails to result in maximising behaviour. He suggests that people adapt well enough by satisficing, so they do not tend to optimise. One of the primary problems for information foraging theory is to understand the mechanisms behind the way in which foragers allocate their time and attention to the most useful of the information sources available to them.

There exist time, resource, and opportunity costs of different information foraging strategies, and these are influenced by the structure of the interface between people and information sources (i.e., the physical layout of the information, functionality, and accessibility of the information). In applying the theory of information foraging, Pirolli and Card (1999) make the assumption that in order to maximise their rate of valuable information gain, people will adapt their strategies (e.g. they may do this through use of a satisficing or an optimising strategy), or if possible, adapt the structure of the interface between them and the information repository (e.g. make the information more accessible by bringing it closer, or organising it more efficiently). They claim that one cognitive strategy will be used in preference to another if it produces more useful information per unit cost. In addition to expecting that information systems (such as internet search engines) will inevitably develop with the aim of improving the returns on information foraging, these authors also suggest that one would expect that, faced with these foraging tasks, cognitive structures and strategies will also gradually develop through learning and practice to maximise the gain per unit cost. It is also possible, however, that people switch between different strategies when foraging for information. In some cases, for example in completely new environments or when searching information for new and specific tasks which the seeker has not encountered before, new foraging strategies may even need to be explicitly taught in order for people to be able to use them. 
Much of the information in a given environment occurs in patches. A patch of information could be a website, different journal papers, pages within a book, etc. When students are allocating time across information sources, the information 'patch' is assumed to be the section of text/information source that the student will abandon when information gain has dropped below a certain threshold. For example, if a patch was a website, then when the student had extracted all the information they felt useful from that site, they would abandon it and move to the next website. If the patch was a page of a book, then the student would leave the page when information gain began to drop below a threshold, and they would move to the next page of that book. It is the job of the forager (in this case, the student) to direct themselves from one of these patches to another. The forager must also decide how to allocate their time to between-patch and within-patch foraging. One way of doing this would be through enrichment, which is when information foragers mould the task environment in order to suit the strategies available to them. Examples of environmental enrichment include: Reducing the average cost of switching information patches (i.e. minimising between-patch foraging costs); and making information patches that yield better returns (i.e. changing the environment in order to improve within-patch foraging outcomes) by, for example, refining keyword queries for a search engine so the list it returns is potentially more relevant. The environment can be modified to minimise between-patch costs and maximise with-in patch results.

An important question that arises here is whether information foraging requires metacognition (i.e. does information foraging require a level of thinking that involves active control over the process of thinking?). Planning how one should approach a learning task, monitoring how much is being understood, and evaluating the progress towards the completion of a task are all skills that are metacognitive in nature. It seems, therefore, due to time and resource limitations, that on-line information searching needs to be monitored in a strategic way, and therefore involves the consideration of these issues when proposing a theory for human behaviour.

\section{A new model of adaptive time allocation}

Recent research (Wilkinson, 2007) has explored the strategies that students use to search for information when learning. A series of experiments, involving eye trackers to follow accurately the eye movements of students, has revealed that students integrate the 
process of quality judgement with their learning. That is, students judge the quality of the information source at the same time as learning from the source, and only leave the source if their learning is below what was expected or desired from that source. If reading to judge the value of information sources was treated as a separate process to reading in order to learn from the information source, then students may adopt a sampling strategy when searching for information. That is, students would sample a variety of sources to judge their quality (in terms of relevance and appropriateness for the current task) and then make the decision of which one to read/study. This 'sampling' strategy to search for the most appropriate information source was not widely used by the participants in the studies conducted by Wilkinson (2007).

Instead, it was apparent that students would judge the appropriateness of the information source at the same time as reading the text to learn. In this manner, they used a strategy based on the principles of satisficing. Satisficing is a decision-making strategy whereby a person ceases to search for alternatives when they find a resource whose expected utility meets or exceeds a previously determined threshold of what the person deems as satisfactory (Byron, 2004). The evaluation process is integrated into the reading phase so that judgement and learning take place simultaneously. Rather than searching for the 'best'/optimal text the student will continue to read anything that is deemed to be satisfactory, that is to say, above a pre-set threshold level of information gain. A student will begin reading a text and continue to read if information gain is high enough, or abandon reading if the text is not seen as useful or informative for the task in hand. The primary aim using this strategy is to learn about the topic and not to pre-judge the texts for usefulness.

It was important to establish when students were making these decision judgements about the information source/text, as this would determine at what level of text the students were making the decision as to whether the text was relevant/desirable or not. Having an understanding of the level of text at which relevance judgements are made is important to the design of on-line texts/materials (discussed in more detail later). Eye tracking studies (Wilkinson, 2007) revealed that these decision judgements were being made on the basis of very small sections of text, which are referred to as patches (as discussed above). If a page of text consists of four paragraphs, then the students will begin reading the first paragraph, make a decision as to whether or not it was relevant, then either continue reading it (if it was relevant) or move/'jump' to the next paragraph (if it was deemed not 
relevant). These decisions as to whether or not the sections of text were relevant were based on an arbitrary pre-set threshold of information gain that the reader subconsciously set prior to searching.

The unit of text with which readers are prepared to satisfice is relatively small. They will not read the first paragraph of a page and decide that the rest of the page is not relevant without first skim-checking the remaining paragraphs. Also, readers will not search the first page of a document and decide the rest of the pages are not relevant without first skimchecking the remaining pages. This suggests that the patch model of time allocation being proposed here operates at more than one level.

This observation informs us that students are very specific in their behaviour when searching for information from on-line texts. They will not waste time judging the texts/sources before choosing one to study, and they will not judge an entire text/source on the basis of its first page/paragraph, without skim-checking the remainder before leaving. This has led to a nested model of adaptive time allocation called the 'satisfice then skim-check strategy', whereby students use paragraphs/sections as a patch with which they can satisfice, but then skim-check the remainder of the paragraphs/sections on the page before moving to the next page. This model explains the search strategies used by students when learning from on-line texts, and has implications for the way in which online education environments should be designed.

\section{Facilitating student learning}

It was previously discussed that the existence of scent cues (Pirolli and Card, 1995) aids the reader in finding the information which s/he desires. However, what is evident from recent eye-tracking studies (Wilkinson, 2007) is the tendency for readers to allocate time across texts when learning for a test by skimming the text and rejecting paragraphs which do not appear to contain the information required. It appears that readers are searching by rejecting, rather than (or in addition to) searching by following cues, and therefore after deciding to reject a certain section of text, they simply move onto the next section of text. In this way, design for skimmability need not only be a matter of clear headings and other scent like cues (Neilsen 1997), but also a matter of making the various patches of a 
document easily perceived and then allowing the moves from one patch to another to be readily made (Reader and Payne, 2007).

If it is known that readers read the first paragraph, or section of a text normally, and then use the paragraph structures to skim read the remainder of the page, then this could inform text designers. It would make sense to put salient information in the first paragraph/section of a text, and then start subsequent paragraphs with important or essential information, since it seems as though it is the content at the start of a paragraph which is responsible for holding the readers' interest, or not. Indeed, it has been suggested in previous research that the first and last sentences of a paragraph are indicative of its content (Masson, 1982). This type of research has implications for online text designers, whose interest may focus on the sections of a text to which readers initially direct their attention. It would be these areas of initial interest where essential or primary information should be placed.

The research discussed in this paper has suggested that skimming a document may not necessarily involve the reader deliberately searching for specific sections of the text, as Pirolli and Card (1999) have termed 'scent following', but rather that skimming could arise from readers rejecting patches (sections of text) and jumping/moving to the next patch simply because it is next. In this way, a 'skimmable' document would be one in which the patches of a text are easily perceived by the reader and where the moves from one patch to the next can be readily made (i.e. a paragraph). Readers 'skim' paragraphs of the text and reject those sections which are below their threshold level for information gain. This is evident from eye tracking data showing that irrelevant sections of text are left earlier than relevant sections of text. Therefore, on the basis of this research, writers of on-line texts could be advised to put salient information at the top of the page, and then other information which they want people to read should be placed at the beginning of each subsequent paragraph, or section of page, since it is these areas of the page which are responsible for holding the readers' attention.

This design of on-line materials is already used and journalists base the content of their writing on an inverted pyramid, placing the salient information at the top, i.e. the base of the pyramid (Ricketson, 2004). They work on the premise that the body of the text should merely amplify what the reader already knows is coming, as they write in such a way that they tell the reader what they want to know as quickly as possible. Also, hotspot plots 
(images indicating focus of attention) created from participants' eye movements in studies conducted by Wilkinson (2007) suggest that important information may be better placed at the left and at the top of the screen, as this is where most attention was directed. This is also illustrated by Google's Golden Triangle, the area shaped like a triangle at the top of the search results page which shows most eye-tracking activity. Eye Tools Eye Tracking research (2006) conducted a study whereby fifty participants were given five different scenarios that required the use of a search engine (Google was used each time). Results revealed that $100 \%$ of people looked at the listings in the top three positions, $85 \%$ of people looked at the fourth listing, $60 \%$ looked at the fifth listing, and only $50 \%$ looked at the sixth. Research also showed that $72 \%$ of users clicked on the first link. This research confirms the importance of the location of information on a page. Neilsen (2006) also showed that readers' attention on a web page appeared to be an F-Shaped pattern. However, the ability of a reader to skim a text may also depend on factors other than the layout of the patches of a text or how perceivable they may be. Factors such as the reader's reading level, their knowledge about the topic, the length of the text, and the cohesion of the text may also influence to what extent the reader is able to skim in their search for information.

Another potential design implication which arises from recent research involves the difficulty of the available texts, rather than the relevance of the texts. Recent research (Wilkinson, 2007) showed that when provided with texts that vary in difficulty, readers had a preference for the easiest text, therefore suggesting that they were sensitive to the level of difficulty of the texts as they read. The most obvious implication of this finding is the fact that people prefer to read easy texts, and so this may advise writers of on-line texts to keep their texts as simple as possible. A hyper-text structure on-line gives users an opportunity to see what the text/document is going to be like in terms of difficulty and style by providing the user with short summaries, headings, or text snippets as an indication of what to expect in the text/document. Such guides not only reveal the content of the text but also other qualities that are relevant to the utility of the text, such as difficulty. This research reinforces the need to allow readers to experience the style and vocabulary of the text as well as the topic before they choose to read, since the preference for the easy text in studies by Wilkinson (2007) suggests that readers would choose simple, easy to read texts over complex ones, especially when under time pressure. It has also been shown that readers will consult aids such as outlines when they are available in order to sample the style and difficulty of the texts (Reader and Payne, 2007). The findings of this 
research may therefore recommend to website and digital library designers that they should perhaps include summaries and headings.

The model discussed here is built upon the premise that people are programmed to strive for maximum benefit in return for minimum effort. Making the search process easier is therefore key to the success of the on-line information source or text. An understanding of the strategies used when students are searching for information under time pressure will thus aid the development of these on-line sources and texts into ones which are easy to navigate and able to support a 'satisficing then skim-checking' model of observed behaviour. The information in on-line sources not only needs to be good, but also it needs to be easy to read and easy to find. When deliberating which on-line source to consult, users will make trade-offs based on two questions; what can I expect to gain from this, and what is the likely cost to discover and consume this information (in terms of time and effort)? (Neilsen, 2003). Based on this assumption that information foragers (e.g. students) will weigh up options in terms of maximum gain for minimum effort, it appears of paramount importance that on-line sources/texts are designed with this in mind.

Along with an increase in the numbers of students choosing to study on-line on distance learning courses and the increasing numbers of higher education institutions who choose to incorporate e-learning into their curricula, it is important to develop an understanding of the ways in which students interact with information on-line. This paper has discussed recent research which focussed on modelling information search behaviour so that on-line courses and materials could be constructed in a manner which facilitates student learning. Minimising information search time by making on-line resources easier to navigate will ultimately facilitate learning. This innovative 'nested' model of adaptive time allocation satisfice then skim-check strategy - gives educational and learning developers an insight into the strategies that students use when searching for information on-line and engaging with virtual learning environments. This model of students' search behaviour can therefore help educators to enhance student learning by designing on-line information sources in such a way that supports this nested model of adaptive time allocation. As discussed above, designing for 'skimmability' by providing clear scent-like cues, small text patches with salient information placed at the beginning of the patch, and using outlines to increase the accuracy of text selection, will all contribute in facilitating the information search and retrieval process of students engaged in e-learning and distance learning courses. 


\section{References}

Byron, M. (2004) Satisficing and maximising: moral theorists on practical reason. Cambridge: Cambridge University Press.

Dennett, D. (1991) Consciousness explained. Boston: Little, Brown.

Eye Tools (2006) Eye tools, enquiro, and did-it uncover search's golden triangle.

ONLINE: www.eyetools.com/inpage/research google eyetracking heatmap.htm (Accessed: 12 April 2009).

Masson, M. E. (1982) 'Cognitive processes in skimming stories', Journal of Experimental Psychology: Learning, Memory and Cognition 8(5) pp 400-417.

Miller, G. A. (1983) 'Informavores', pp. 111-113, in Machlup, F. and Mansfield, U. (eds.) The study of information: interdisciplinary messages. New York: Wiley.

Neilsen, J. (1997) Alert box: be succinct! Writing for the web. ONLINE: www.useit.com/alertbox/9703b.html (Accessed: 12 April 2009).

Neilsen, J. (2003) Alert box: information foraging: why Google makes people leave your site faster. ONLINE: www.useit.com/alertbox/20030630.html (Accessed: 1 May 2009).

Neilsen, J. (2006) Alert box: F-shaped pattern for reading web content. ONLINE: www.useit.com/alertbox/reading pattern.html (Accessed: 06 June 2009).

O'Connor, B. (1993) 'Browsing: a framework for seeking functional information', Knowledge: Creation, Diffusion, Utilization 15(2) pp 211-232.

Pirolli, P. and Card, S. (1995) 'Information foraging in information access environments', SIGCHI conference on human factors in computing systems, Denver, Colorado, USA, 7-11 May. 
Pirolli, P. and Card, S. (1999) 'Information foraging', Psychological Review 106(4) pp 643-675.

Reader, W. and Payne, S. (2007) 'Allocating time across multiple texts', Journal of Human Computer Interaction 22(3) pp 263-298.

Rice, R.E., McCreadie, M.M. and Chang, S.J. (2001) Accessing and browsing information and communication. Cambridge, MA: MIT Press.

Ricketson, M. (2004) Writing feature stories: how to research and write newspaper and magazine articles. Sydney: Allen and Unwin.

Sandstrom, P. E. (1994) 'An optimal foraging approach to information seeking and Use', Library Quarterly 64(4) pp 414-449.

Simon, H. A. (1976) Administrative behaviour: a study of decision-making processes in administrative organization ( $3^{\text {rd }}$ edn). New York: Free Press.

Son, L. K. and Metcalfe, J. (2000) 'Metacognitive and control strategies in study-time allocation', Journal of Experimental Psychology: Learning, Memory and Cognition 26(1) pp 204-221.

Thiede, K.W. and Dunlosky, J. (1999) 'Toward a general model of self-regulated study: an analysis of selection of items for study and self-paced study time', Journal of Experimental Psychology: Learning, Memory and Cognition 25(4) pp 1024-1037.

Wilkinson, S.C. (2007) Strategies for time allocation across multiple on-line texts. Unpublished PhD Thesis. Cardiff University.

\section{Author Details}

Susan is currently working as an e-learning developer at the University of Wales Institute Cardiff. Prior to this she was a senior learning developer at a HEFCE-funded CETL based at Portsmouth University, researching and developing online materials for 
work-based distance learners. She has also taught Psychology at Portsmouth University and for the Open University. Her PhD examined readers' browsing strategies and information foraging theory, and current research interests include the psychological processes of learning, e-learning, and learner development. 